\title{
Sitagliptin prevents aggravation of endocrine and exocrine pancreatic damage in the Zucker Diabetic Fatty rat - focus on amelioration of metabolic profile and tissue cytoprotective properties
}

Cristina Mega ${ }^{1,2}$, Helena Vala ${ }^{2,3}$, Paulo Rodrigues-Santos ${ }^{4,5}$, Jorge Oliveira ${ }^{2,3}$, Frederico Teixeira ${ }^{1}$, Rosa Fernandes ${ }^{1}$, Flávio Reis ${ }^{{ }^{*}+}$ and Edite Teixeira de Lemos ${ }^{1,2 \dagger}$

\begin{abstract}
Background: The purpose of this study was to investigate some of the possible mechanisms underlying the protective effects of a dipeptidyl peptidase IV (DPP-IV) inhibitor, sitagliptin, on pancreatic tissue in an animal model of type 2 diabetes mellitus (T2DM), the Zucker Diabetic Fatty (ZDF) rat, focusing on glycaemic, insulinic and lipidic profiles, as well as, on apoptosis, inflammation, angiogenesis and proliferation mediators.

Methods: Male obese diabetic ZDF (fa/fa) rats, aged 20 weeks, were treated with sitagliptin $(10 \mathrm{mg} / \mathrm{kg}$ bw/day) during 6 weeks and compared to untreated diabetic and lean control littermates. Metabolic data was evaluated at the beginning and at the end of the treatment, including glycaemia, HbA1c, insulinaemia, HOMA-beta and TGs. Endocrine and exocrine pancreas lesions were assessed semiquantitatively by histopathological methods. Pancreas gene (mRNA) and protein expression of mediators of apoptotic machinery, inflammation and angiogenesis/ proliferation (Bax, BCI2, IL-1 $\beta$, VEGF, PCNA and TRIB3) were analyzed by RT-qPCR and/or by immunohistochemistry.

Results: Sitagliptin treatment for 6 weeks (between 20 and 26 week-old) was able to significantly $(p<0.001)$ ameliorate all the metabolic parameters, by preventing the increase in blood glucose and in serum TGs contents (16.54\% and $37.63 \%$, respectively, vs untreated), as well as, by preventing the decrease in serum insulin levels and in the functional beta cells capacity accessed via HOMA-beta index (156.28\% and $191.74 \%$, respectively, vs untreated). Sitagliptin-treated diabetic rats presented a reduced pancreas Bax/Bcl2 ratio, suggestive of an antiapoptotic effect; in addition, sitagliptin was able to completely reduce $(p<0.001)$ the pancreas overexpression of IL-1 $\beta$ and TRIB3 found in the untreated diabetic animals; and promoted a significant $(p<0.001)$ overexpression of VEGF and PCNA.

Conclusion: In this animal model of obese T2DM (the ZDF rat), sitagliptin prevented $\beta$-cell dysfunction and evolution of pancreatic damage. The protective effects afforded by this DPP-IV inhibitor may derive from improvement of the metabolic profile (viewed by the amelioration of glucose and TGs levels and of insulin resistance) and from cytoprotective properties, such as antiapoptotic, anti-inflammatory, pro-angiogenic and pro-proliferative.
\end{abstract}

Keywords: Type 2 diabetes, Endocrine and exocrine pancreas lesions, Sitagliptin, Cytoprotective properties, ZDF rat

\footnotetext{
* Correspondence: freis@fmed.uc.pt

${ }^{\dagger}$ Equal contributors

'Laboratory of Pharmacology \& Experimental Therapeutics, IBILI, Faculty of Medicine, Sub-Unit 1 (Polo III), University of Coimbra, 3000-548 Coimbra,

Portugal

Full list of author information is available at the end of the article
} 


\section{Background}

Type 2 diabetes mellitus (T2DM) prevalence and incidence is rapidly increasing worldwide; it is predicted, according to the latest estimates of the World Health Organization (WHO), that diabetes will be the 7th leading cause of death in 2030 [1]. T2DM is a chronic disease leading to macroand microvascular complications, which results in severe illness and premature death, with elevated personal and economic costs $[2,3]$.

The central features of T2DM are a defect in insulin resistance and/or insulin secretion, which lead to hyperglycaemia; disruption of the normal relationship between insulin sensitivity and pancreatic $\beta$-cell function is a hallmark of T2DM progression [4]. In fact, degeneration of Langerhans islets with $\beta$-cell loss is secondary to insulin resistance and is regarded as the most important lesion for progression of the disease [5,6]. As $\beta$-cell function declines, the impairment of insulin action becomes more important. Hyperglycaemia, per se, may have a detrimental effect on secretory function, - "glucotoxicity" -, which induces increased apoptosis in pancreatic islets; in addition, the abnormal lipid profile commonly observed in these subjects may be associated with functional impairment of the islet - "lipotoxicity" [5-8].

Current knowledge adds further complexity in the picture of T2DM pathogenesis by including the role of incretin hormones. Incretins [gastric inhibitory polypeptide (GIP) and glucagon-like peptide-1 (GLP-1)] are peptide hormones secreted in the gastrointestinal mucosa after meal ingestion. These are released in response to oral glucose intake and are able to attain physiological concentrations causing insulin release, which is called the "incretin effect" [9-12]. GLP1 acts in a positive way on the $\beta$ and $\delta$ cells, whereas GIP acts preferentially on $\alpha$ and $\beta$ cells. These peptides are almost undetectable during fasting and exist only in high concentrations in the postprandial state, since they are rapidly metabolized [13] by the ubiquitous enzyme, dipeptidyl peptidase-IV (DPP-IV), to inactive metabolites, which are eliminated by urine [14]. The incretin effect is responsible for about $60 \%$ of the secretion of postprandial insulin, which is decreased in T2DM [15]. In these patients, the incretin effect is stifled, producing an "incretin defect". This condition occurs as a result of reduced secretion of GLP-1, accelerated metabolism of GLP-1 and GIP, as well as defective response to both hormones, particularly to the insulinotropic effect of GIP [16,17]. The key mechanisms by which these factors exert their action on $\beta$-cells are not yet completely elucidated, but currently lie on metabolic processes such as apoptosis and inflammation, among others putatively involved.

Low-grade inflammation has been viewed as a major player in insulin resistance development and T2DM evolution; indeed, hyperglycaemia seems to induce the production of acute phase reactants from the adipose tissue, while obesity, present in many diabetic patients, is in itself, characterized as a state of low grade inflammation [18]. T2DM is found to display increased concentrations of C-reactive protein (CRP) and pro-inflammatory cytokines, such as tumor necrosis factor- $\alpha$ (TNF- $\alpha)$ and interleukins 1 and 6 (IL-1, IL-6), which are implicated in instigating metabolic insulin resistance [19]. However, it is not still clear which is the cause and/or the consequence. A recent study by Martin-Cordero et al. [20] using obese fa/fa obese Zucker rats confirmed the presence of augmented inflammatory markers (IL-6 and CRP) in metabolic syndrome (MS), together with increased noradrenaline contents; the authors postulate that those results may reflect a defective regulation of the negative inflammatory/stress feedback loop under those circumstances, suggesting that MS could be either the cause or the consequence of diabetes associated with obesity.

Additionally, although the loss of $\beta$-cell mass is not yet completely clarified, apoptosis seems to be involved, as previously observed in pancreas at autopsy and isolated islets from people with T2DM [21,22]. Based on these assumptions, it is becoming clear that T2DM management, namely by using pharmacological agents, must envision not only glycaemic control but also, and particularly, the mechanisms behind progression of pancreatic deterioration and underlying evolutional complications. In fact, T2DM therapeutics should be able to preserve $\beta$-cell mass as the mainstay of disease control, by addressing the mechanisms implicated in diabetic pathogenesis, including apoptosis, inflammation or even an added capacity for cell proliferation.

Enhancing the incretin effect is now a possible therapeutic target in T2DM, using GLP-1 analogues or DPP-IV inhibitors. Sitagliptin belongs to a class of oral antidiabetic drugs, the gliptins, which inhibit the enzyme DPP-IV that degrades incretins, prolonging the physiological actions of GLP-1 [23,24]. GLP-1, a prominent active compound of the incretin family, modulates many processes in pancreatic islet: it potentiates insulin synthesis and secretion [25], inhibits glucagon secretion [26], increases islet cell proliferation, and decreases cell apoptosis [27,28]. Our group has previously shown that sitagliptin is able to ameliorate dysmetabolism, insulin resistance, inflammation and oxidative stress in an animal model of T2DM, the Zucker Diabetic Fatty (ZDF) rat $[29,30]$. Thus, the purpose of the current study was to investigate some of the possible mechanisms underlying the protective effects produced by chronic sitagliptin treatment on pancreatic tissue in the ZDF rat, focusing on apoptosis, inflammation, angiogenesis and proliferation mediators.

\section{Methods}

\section{Animals and experimental design}

Male ZDF rats (ZDF/Gmi, $f a / f a)$ and their littermates (ZDF/Gmi, +/+) were purchased from Charles River 
Laboratories (Barcelona, Spain) with 6 weeks of age and kept in our animal facility until they reached 20 weeks of age. Rats were properly housed, handled daily, and kept at a controlled standard temperature $\left(22-23^{\circ} \mathrm{C}\right)$, humidity $(60 \%)$ and light-dark cycles $(12 / 12 \mathrm{~h})$. Throughout the experiment, the animals were provided with distilled water ad libitum and rodent maintenance chow (A-04 Panlab, Barcelona, Spain, containing 15.4\% of protein and $2.9 \%$ of lipids). The chow was adapted to the animal's body weight (BW): $100 \mathrm{mg} / \mathrm{g}$. Animal experiments were conducted according the European Council Directives on Animal Care and the National Laws. Along the text and in order to simplify the description of the animals, the ZDF/Gmi, $f a / f a$ rats will be designated as diabetic rats, and, when under sitagliptin treatment, as sitagliptin-treated diabetic rats. The ZDF/Gmi, +/+ rats will be designated as lean control or control rats. The initial groups were established as 15 diabetic rats and as 10 lean control rats. When aged 20 weeks, $\mathrm{n}=5$ obese diabetic ZDF rats and the lean control $(n=5)$ were sacrificed for blood and tissue collection in order to establish the basal levels. The remainder lean control rats followed to week 26, as well as, the diabetic ZDF rats which were divided in two sub-groups $(n=5$ rats each). The sitagliptin-treated group received by oral gavage, once a day (6:00 PM), during 6 weeks, $10 \mathrm{mg} / \mathrm{kg} / \mathrm{BW}$ of sitagliptin dissolved in orange juice (vehicle) and the diabetic untreated group received, in the same conditions, only the vehicle (orange juice). The same procedures were adopted with the lean control rats. At 26 weeks of age, the animals were sacrificed by anaesthetic overdose, blood and tissues were collected for different analyses.

\section{Glycaemic, insulinaemic and lipidic profile assays}

Serum glucose levels were measured using a Glucose oxidase commercial kit (Sigma, St. Louis, Mo, USA). Considering the variability of serum glucose levels in the rat, glycosylated haemoglobin (HbA1c) levels were used as an index of glucose control, through the DCA 2000+ latex immunoagglutination method (Bayer Diagnostics, Barcelona, Spain). Plasma insulin levels were quantified by using a rat insulin Elisa assay kit from Mercodia (Uppsala, Sweden). The steady state beta cell function of individual animals was evaluated using the previously validated homeostasis model assessment (HOMA) of $\beta$-cell function [31]. The formula used was as follows: $[$ HOMA $-\beta \%]=360 \times$ fasting serum insulin $(\mathrm{mU} / \mathrm{L}) /$ fasting serum glucose $(\mathrm{mg} / \mathrm{dl})-63$. The values used (insulin and glucose) were obtained after an overnight of food deprivation. Serum triglycerides (TGs) were analysed on a Hitachi 717 analyser (Roche Diagnostics) using standard laboratorial methods. TGs kit was obtained from bioMérieux ${ }^{\oplus}$ (Lyon, France).

\section{Endocrine and exocrine pancreas lesions analysis by histopathology \\ Sample collection and preparation}

The pancreas was immediately removed, placed in icecold Krebs' buffer and carefully cleaned of extraneous fat and connective tissue; then the organ was cross-sectioned, fixed and processed for paraffin embedding in compliance with the histological protocols used.

\section{Hematoxilyn \& eosine staining}

Samples were fixed in Bock's fixative, embedded in paraffin wax and $3 \mu \mathrm{m}$ thick sections were stained for routine histopathological diagnosis with haematoxylin and eosin (HE). All samples were examined by light microscopy using a Microscope Zeiss Mod Axioplan 2. Image acquisition was performed with digital microscope camera (Leica DFC450) and image processing was performed with the LAS Advanced Analysis Software Bundle (No: 12730448.). The degree of injury visible by light microscopy was scored in a double blind fashion. Assessment of mean islet number: Islets were counted using a $10 \times$ magnification, in three different microscopic fields and, the mean number per field was calculated for each study group. Assessment of islet size: Islet dimensions were obtained by measuring its maximum girth with an ocular grid of $1000 \mu \mathrm{m}$, using a 10× magnification. The maximum diameter was found by comparing all available radii diameters of each islet, and choosing the greatest. Islets were evaluated in three different microscopic fields and the mean size of the islets from each group of rats was calculated.

\section{Histopathology}

Appreciation of islet architecture was based on the uniformity of islet boundaries and classified as regular or irregular. Endocrine pancreatic damage was assessed by evaluating changes in the islets of Langerhans, namely, islet architecture (shape), presence of inflammatory infiltrate, fibrosis, and vacuolization and intra-islet congestion. A semi-quantitative rating for each slide ranging from 0 (minimal) to 3 (severe and extensive damage) was assigned to each of the studied components: inflammatory infiltrate, congestion, vacuolization and fibrosis. Each islet was examined and scored. Severity was graded as 0 = absent, 1 = mild, $2=$ moderate and $3=$ severe. Extension was evaluated by the area occupied by the lesion, an area of $<25 \%$ of the islet, was scored as 0 , an area $25-50 \%$ scored as 1 , an area $50-75 \%$ scored as 2 , and if detected in an area $>75 \%$ scored as 3 . The final score of each sample was obtained by the average of scores observed in individual islets. Exocrine pancreatic damage was evaluated according to the presence of congestion, fibrosis and inflammatory infiltrate in the interstitial tissues and graded also, by the same semiquantitative method, considering the 
entire exocrine parenchyma on the slide, as previously described [29].

\section{Periodic acid of schiff staining}

Periodic Acid of Schiff (PAS) was used to confirm the levels of islet and exocrine fibrosis. Samples were fixed in neutral formalin 10\%, embedded in paraffin wax and $3 \mu \mathrm{m}$ thick sections were immersed in water and subsequently treated with a $1 \%$ aqueous solution of periodic acid, then washed to remove any traces of the periodic acid and finally treated with Schiff's reagent. A semi-quantitative rating was set for intensity and extension of staining, ranging from 0 (no staining) to 3 (intense and extensive staining).

\section{Pancreatic protein expression by immunohistochemistry}

Formalin-fixed and paraffin embedded tissues were cut into $3 \mu \mathrm{m}$ sections and deparaffinised in xylene. $3 \% \mathrm{H}_{2} \mathrm{O}_{2}$ was used to remove endogenous peroxidase, and citrate buffered saline ( $\mathrm{pH}$ 6.0), in MO, was used for antigen retrieval. Sections were preincubated with normal rabbit serum to prevent nonspecific binding and then incubated overnight at $4^{\circ} \mathrm{C}$ with anti-Bax $(\Delta 21,1: 50$, rabbit polyclonal antibody, Santa Cruz, Biotechnology), Bcl2 (C 21, 1:50, rabbit polyclonal antibody, Santa Cruz, Biotechnology) and TRIB3 (ab22107, 1:100, rabbit polyclonal antibody, Abcam). The sections were then sequentially incubated at room temperature, with labelled-(strept)avidin-biotin-peroxidase method (LAB-SA) (Histostain-Plus kit Zymed). Negative controls were included in each staining series, by omission of the primary antibodies. Positive controls were, respectively for Bax, Bcl2 and TRIB3 canine tonsils, canine breast carcinoma and the rat exocrine pancreas. Sections were counterstained with hematoxylin. The results were examined by light microscopy using a Zeiss Axioplan 2 microscope. Image acquisition and processing was performed according to described in the previous section. Immunopositivity was scored in accordance to staining intensity (I) and percentage of positive cells (P). Staining intensity was evaluated as 0 , undetectable; 1 , weak staining; 2 , moderate staining and 3 , intensive staining. Positive cells were evaluated in all Islets' of Langerhans present on the slide. Final scoring for each rat was calculated by the Quick Score $(\mathrm{Q})$ in which the percentage of positive cells $(\mathrm{P})$ is multiplied by the intensity (I), using the formula: $\mathrm{Q}=\mathrm{P} \times \mathrm{I}$, resulting in a score between $0-300$ [32]. The final score for each group was found by mean average.

\section{Pancreatic gene (mRNA) expression analysis by RT-qPCR Sample collection and preparation}

The pancreas were immediately collected, placed in ice-cold Krebs buffer for cleaning of collective tissue and immediately frozen at $-80^{\circ} \mathrm{C}$ in preservative RNA later $^{\mathrm{Tw}}$ solution (Ambion, Austin, TX, USA) until analysis. Gene (mRNA) expression was evaluated by real-time
RT-qPCR for markers of apoptotic machinery, inflammation and proliferation/angiogenesis.

\section{Total RNA isolation}

Samples were removed from the RNA later ${ }^{\text {rm }}$ preservation solution and $1200 \mu \mathrm{L}$ of RLT Lysis Buffer was added to proceed with disruption and homogenization for $2 \mathrm{~min}$ at $30 \mathrm{~Hz}$ using TissueLyser (Qiagen, Hilden, Germany). Tissue lysate were processed according to the protocol from RNeasy ${ }^{\circ}$ Mini Kit (Qiagen, Hilden, Germany). Total RNA was eluted in $50 \mu \mathrm{L}$ of RNase-free water (without optional treatment with DNAse). In order to quantify the amount of total RNA extracted and verify RNA integrity (RIN, RNA Integrity Number), samples were analysed using 6000 Nano Chip $^{\circ}$ kit, in Agilent 2100 bioanalyser (Agilent Technologies, Walbronn, Germany) and 2100 expert software, following manufacturer instructions. The yield from isolation was from 0.5 to $3 \mu \mathrm{g}$; RIN values were 6.0-9.0 and purity $\left(\mathrm{A}_{260} / \mathrm{A}_{280}\right)$ was 1.8-2.0.

\section{Reverse transcription}

RNA was reverse transcribed with SuperScript ${ }^{\mathrm{tm}}$ III firststrand synthesis system for RT-PCR (Invitrogen, California, USA). One microgram of total RNA was mixed with a $2 \times$ First-Strand Reaction Mix and a SuperScript ${ }^{\mathrm{Tm}}$ III Enzyme Mix (Oligo(dT) plus Random hexamers). Reactions were carried out in a thermocycler Gene Amp PCR System 9600 (Perkin Elmer, Norwalk, CT, USA), $10 \mathrm{~min}$ at $25^{\circ} \mathrm{C}$, $50 \mathrm{~min}$ at $50^{\circ} \mathrm{C}$ and $5 \mathrm{~min}$ at $85^{\circ} \mathrm{C}$. Reaction products were then digested with $1 \mu \mathrm{L}$ RNase $\mathrm{H}$ for $20 \mathrm{~min}$ at $37^{\circ} \mathrm{C}$ and, finally, cDNA eluted to a final volume of $100 \mu \mathrm{L}$ and stored at $-20^{\circ} \mathrm{C}$.

\section{Relative quantification of gene expression}

Performed using 7900 HT Sequence Detection System (Applied Biosystems, Foster City, CA, USA). A normalization step preceded the gene expression quantification, using geNorm Housekeeping Gene Selection kit for Rattus norvegicus (Primer Design, Southampton, UK) and geNorm software (Ghent University Hospital, Center for Medical Genetics, Ghent, Belgium) to select optimal housekeeping genes to this study [33]. Real-time PCR reactions used specific QuantiTect Primer Assays (Qiagen, Hilden, Germany) with optimized primers for Bax, Bcl2, TRB3, IL-1 $\beta$, PCNA and VEGF. Endogenous controls were also used: GAPDH, ACTB, TOP1, and RPL13 together with QuantiTect SYBR Green PCR Kit Gene expression (Qiagen, Hilden, Germany) according to manufacturer's instructions. RT-qPCR reactions were carried out with $100 \mathrm{ng}$ cDNA sample, primers (50-200 nM) and 1X QuantiTect SYBR Green PCR Master Mix. Nontemplate control reactions were performed for each gene, in order to assure no unspecific amplification. Reactions were performed with the following thermal profile: $10 \mathrm{~min}$ 
at $95^{\circ} \mathrm{C}$ plus 40 cycles of $15 \mathrm{~s}$ at $95^{\circ} \mathrm{C}$ and $1 \mathrm{~min}$. at $60^{\circ} \mathrm{C}$. Real-time PCR results were analyzed with SDS 2.1 software (Applied Biosystems, Foster City, CA, USA) and quantification used the $2^{-\Delta \Delta C t}$ method [34].

\section{Statistical analysis}

For all biochemical measurements made over time and treatment effect, independent samples t-Student test was used. For histopathology and immunohistochemistry data: Chi-square test with Monte Carlo simulation or exact test (when contingency tables are $2 \times 2$ ) was performed to find out the differences in lesions of endocrine/exocrine pancreas between lean control and diabetic ZDF rats at the beginning of the study, (20 week-old); untreated and sitagliptin treated diabetic ZDF and lean control rats at 26 weeks of age. Independent samples t-Student test was used to determine the differences in the number, regularity and size of the pancreatic islets between lean control and diabetic ZDF rats in the pre-therapeutic stage, at 20 weeks; untreated and sitagliptin-treated diabetic ZDF and lean control ZDF rats at 26 weeks of age. Data were analysed using SPSS Statistics 20 (2011). For RT-qPCR data: For statistical analysis, we used the GraphPad Prism, Version 5.0. Comparisons between groups were performed using ANOVA and the post-hoc Bonferroni test. All values are reported as mean \pm SEM (standard error of means). Significance level was accepted at 0.05.

\section{Results}

\section{Sitagliptin prevents aggravation of glycaemic,} insulinaemic and lipidic profiles

Concerning body weight, no significant differences were encountered between the diabetic and the lean control rats at the beginning of treatments (T0: week 20), despite the obese profile encountered in the diabetic rats between the 8th and the 14th week (data not shown). At the end of the study (26 weeks), the untreated diabetic rats exhibited a reduction in their BW $(\mathrm{p}<0.001)$; nevertheless, the lean control group gained weight. Sitagliptin treatment, during 6 weeks, stabilized the loss of weight in the diabetic ZDF rats, even preventing part of the BW loss when compared with the rats without treatment (Table 1).

At the beginning of treatments (T0: week 20), fasting blood glucose, HbA1c and TG were already significantly higher in diabetic rats when compared with their lean counterparts, indicative of a metabolic deregulation. These results were accompanied by a decrease in fasting serum insulin and in the functional ability of the pancreas demonstrated by the reduction of $87.99 \%$ in HOMA-beta values. An age-dependent increase in the metabolic deregulation was observed in diabetic untreated ZDF rats presenting augmented levels of glucose, HbA1c and TG from 20 to 26 weeks old. They also exhibit an aggravation of the relative insulinopaenia, as well as a decrease in estimated steady-state beta cell function $(p<0.001)$. Six weeks of sitagliptin treatment was able to significantly ameliorate all the metabolic parameters as shown in Table 1. In fact, sitagliptin significantly $(p<0.001)$ prevented the additional increase in blood glucose and serum TG contents (16.54\% and $37.63 \%$, respectively, vs untreated), while preventing further decrease in serum insulin and enhancing the functional capacity of beta cells (156.28\% and $191.74 \%$, respectively, vs untreated) (Table 1 ).

\section{Sitagliptin prevents aggravation of endocrine and exocrine pancreatic damage}

Comparative analysis between the endocrine pancreas of lean control and diabetic ZDF rats of 20 weeks of age revealed a significant increase in inflammation and fibrosis of Langerhans islets in the diabetic group $(p<0.01)$, with no statistically significant differences in the other analyzed parameters (data not shown). At 26 weeks of age, endocrine pancreatic inflammation was significantly higher $(p<0.001)$ in the diabetic rats when compared with the lean control animals (Figure 1A, B and G). Sitagliptin-treated diabetic ZDF rats showed significantly $(p<0.001)$ reduced inflammation when compared with the untreated diabetic rats (Figure 1B, C and G). A similar profile was encountered concerning endocrine pancreatic fibrosis, which, despite the differences, did not reach statistical significance (Figure 1D-H).

Concerning the exocrine pancreas lesions, in rats aged 26 week-old, while no significant changes were found concerning exocrine pancreas inflammation (Figure $2 \mathrm{~A}-\mathrm{C}$ and $\mathrm{G})$, fibrosis was significantly $(p<0.05)$ increased in the diabetic ZDF rats, when compared with the lean control, which was prevented in the diabetic animals under sitagliptin therapy (Figure 2D-H).

\section{Cytoprotective effects of sitagliptin against pancreatic damage progression}

Pancreatic tissue mRNA levels of mediators of apoptotic machinery showed a significantly increased $(p<0.05)$ expression of the apoptotic Bax, as well as, antiapoptotic $\mathrm{Bcl} 2$ in the 26 week-old diabetic ZDF rats (Figure 3A and $\mathrm{B}$, respectively), when compared with the lean ZDF animals, thus resulting in an unchanged $\mathrm{Bax} / \mathrm{Bcl} 2$ ratio (Figure $3 \mathrm{C}$ ). In the diabetic rats under sitagliptin treatment, there was an overexpression of the mRNA for both $\mathrm{Bax}$ and $\mathrm{Bcl} 2$, favouring a reduced $\mathrm{Bax} / \mathrm{Bcl} 2$ ratio (Figure $3 \mathrm{~A}-\mathrm{C}$ ) as a result of a higher increment of mRNA expression of $\mathrm{Bcl} 2$ when compared with Bax.

The pancreatic mRNA expression of $\mathrm{Bax}$ and $\mathrm{Bcl} 2$ was accompanied by protein expression studies of immunohistochemistry (Figure 3D-L). In the untreated diabetic animals there was a significantly $(p<0.05)$ rise in Bax stained cells and unchanged $\mathrm{Bcl} 2$, resulting in a trend to an increased $\mathrm{Bax} / \mathrm{Bcl} 2$ ratio, when compared with the 
Table 1 Body weight and glycaemic, insulinaemic and lipidic profile in the rats under study at the initial and final times

\begin{tabular}{|c|c|c|c|c|c|}
\hline \multirow{3}{*}{$\begin{array}{c}\text { Time } \\
\text { Groups } \\
\text { Parameters }\end{array}$} & \multicolumn{2}{|c|}{ Initial time ( 20 wks old rats) } & \multicolumn{3}{|c|}{ Final time ( 26 wks old rats) } \\
\hline & \multirow{2}{*}{$\begin{array}{c}\text { Control } \\
\text { Vehicle }(n=10)\end{array}$} & \multirow{2}{*}{$\begin{array}{c}\text { Diabetic } \\
\text { Vehicle }(n=15)\end{array}$} & \multirow{2}{*}{$\begin{array}{c}\text { Control } \\
\text { Vehicle }(n=5)\end{array}$} & \multicolumn{2}{|c|}{ Diabetic } \\
\hline & & & & Vehicle $(n=5)$ & Sitagliptin $(n=5)$ \\
\hline BW (g) & $406.70 \pm 6.83$ & $388.10 \pm 8.87$ & $445.70 \pm 8.16$ & $354.40 \pm 8.85^{\text {aaa }}$ & $380.00 \pm 14.46$ \\
\hline Glucose (mg/dl) & $131.80 \pm 1.20$ & $512.00 \pm 4.53^{\text {aаa }}$ & $133.40 \pm 2.16$ & $623.60 \pm 7.30^{\mathrm{bb}}$ & $520.44 \pm 3.31^{\mathrm{ccc}}$ \\
\hline $\mathrm{HbA1c}(\%)$ & $3.66 \pm 0.15$ & $9.96 \pm 0.86^{\text {aaa }}$ & $3.76 \pm 0.26$ & $10.68 \pm 0.75$ & $8.68 \pm 0.37^{c c c}$ \\
\hline Insulin (mU/ml) & $14.82 \pm 3.90$ & $11.62 \pm 1.15^{\text {aaa }}$ & $15.13 \pm 3.34$ & $7.16 \pm 1.14^{\mathrm{bbb}}$ & $11.19 \pm 1.73^{\mathrm{ccc}}$ \\
\hline HOMA-Beta (\%) & $77.70 \pm 2.28$ & $9.33 \pm 0.83^{\text {aaa }}$ & $77.52 \pm 1.10$ & $4.60 \pm 0.16^{\mathrm{bbb}}$ & $8.82 \pm 0.32^{c c c}$ \\
\hline $\mathrm{TGs}(\mathrm{mg} / \mathrm{dl})$ & $111.60 \pm 8.33$ & $366.00 \pm 5.92^{\text {aaa }}$ & $158.40 \pm 6.80$ & $409.80 \pm 8.04^{\mathrm{bb}}$ & $255.60 \pm 3.70^{c c c}$ \\
\hline
\end{tabular}

Values are means \pm SEM of $n$ rats. Comparisons between groups: ${ }^{\text {aaa }}=p<0.001$ between diabetic versus control groups (20 or 26 weeks); ${ }^{\text {bb }}$ and ${ }^{\text {bbb }}=p<0.01$ and $\mathrm{p}<0.001$, respectively, within the diabetic group ( 26 versus 20 weeks); ${ }^{c c c}=p<0.001$ between diabetic sitagliptin-treated versus diabetic untreated groups (at 26 weeks).

controls; sitagliptin-treated diabetic rats presented a trend for increased protein expression of Bax, accompanied by a significantly $(p<0.001)$ increased expression of $\mathrm{Bcl} 2$, which results in a $\mathrm{Bax} / \mathrm{Bcl} 2$ ratio identical to that found for the control animals (Figure 3D-L).

Concerning other putative mechanisms behind the protective effects of sitagliptin on the pancreatic tissue, we found that the diabetic rats, aged 26 weeks, presented a significantly increased pancreatic mRNA expression of IL-1 $\beta(p<0.01)$, which was prevented $(p<0.001)$ in the sitagliptin-treated group (Figure 4A). Sitagiptin was able to promote overexpression $(p<0.001)$ of VEGF and PCNA mRNA when compared with the untreated diabetic rats (Figure $4 \mathrm{~B}$ and $\mathrm{C}$, respectively). In addition, sitagliptin treatment totally $(p<0.001)$ prevented the diabetes-induced increment $(p<0.001)$ in TRIB3 expression in the pancreatic tissue (Figure 5A-D).

\section{Discussion}

Previous studies propose that a disruption of the normal relationship between insulin sensitivity and pancreatic $\beta$-cell function is crucial for the pathogenesis of T2DM [4], and that the degeneration of Langerhans islets with $\beta$-cell loss is secondary to insulin resistance and may have a key role in the progression of the disease $[5,6]$. Furthermore, the loss of $\beta$-cell mass is not yet completely elucidated, but a possible cause may reside in apoptotic processes and in a lost capacity for pancreatic regeneration $[28,35,36]$. Previous studies have been suggesting that gliptins are able to preserve both $\beta$-cell function and cell mass in animal models of diabetes [29,37-39], but the mechanisms underlying the protective effects remain to be elucidated.

Consistent with previous reports our study demonstrated that a 6 weeks sitagliptin treatment was able to improve $\beta$-cell function as well as preserve pancreatic islet structure. We hypothesize that sitagliptin is able to preserve pancreatic function by improving insulin resistance and by other cytoprotective properties, including antiapoptotic, anti-inflammatory and pro-proliferative, based on the cytoprotective properties previously reported for incretin peptides in distinct tissues [29,37-43]. In fact, the results presented herein strongly suggest that in diabetic ZDF rats sitagliptin may derive its cytoprotective effects via two different type of influences: directly reducing apoptosis and promoting cell proliferation due to increase incretin availability; indirectly via metabolic effects, including amelioration of chronically elevated glucose and triglycerides, prevention of insulinopaenia and reduction of inflammation, thus protecting from deleterious effects derived from glucotoxicity, lipotoxicity and insulin resistance.

The histomorphological evaluation of endocrine and exocrine pancreatic tissue shows that the differences between diabetic untreated and sitagliptin-treated animals were striking. In fact, the sitagliptin-treated rats presented an amelioration of inflammation and fibrosis in endocrine and exocrine pancreas. In particular, inflammation was highly reduced in the islets of Langerhans, and the exocrine pancreas of diabetic rats receiving sitagliptin did not present fibrotic changes in the vascular and the ductal walls. The changes described above were repeatedly and systematically observed by two pathologists unaware of the identity of the slides. These findings are in accordance with our preliminary work [29] but in contradiction with the results obtained by Matveyenko et al. [37] using a DPP IV inhibitor in human IAPP transgenic (HIP) rats and by Nachnani et al. [41] using an injection of GLP-1 agonist, who suggest that the enhancement of endogenous GLP-1 levels could induce undetected low grade asymptomatic chronic pancreatitis. The histomorphological observations were in accordance with an improvement in pancreatic beta-cell function as shown by the augmentation in HOMA-beta in diabetic sitagliptin-treated rats. The effects of chronic inhibition of DPP-IV in increasing $\beta$-cell mass and function over time could be due, at least in part, by the increase in glucose-stimulated insulin secretion, which is believed to be mediated primarily via stabilization of the incretin hormones, including GLP-1 [27]. 


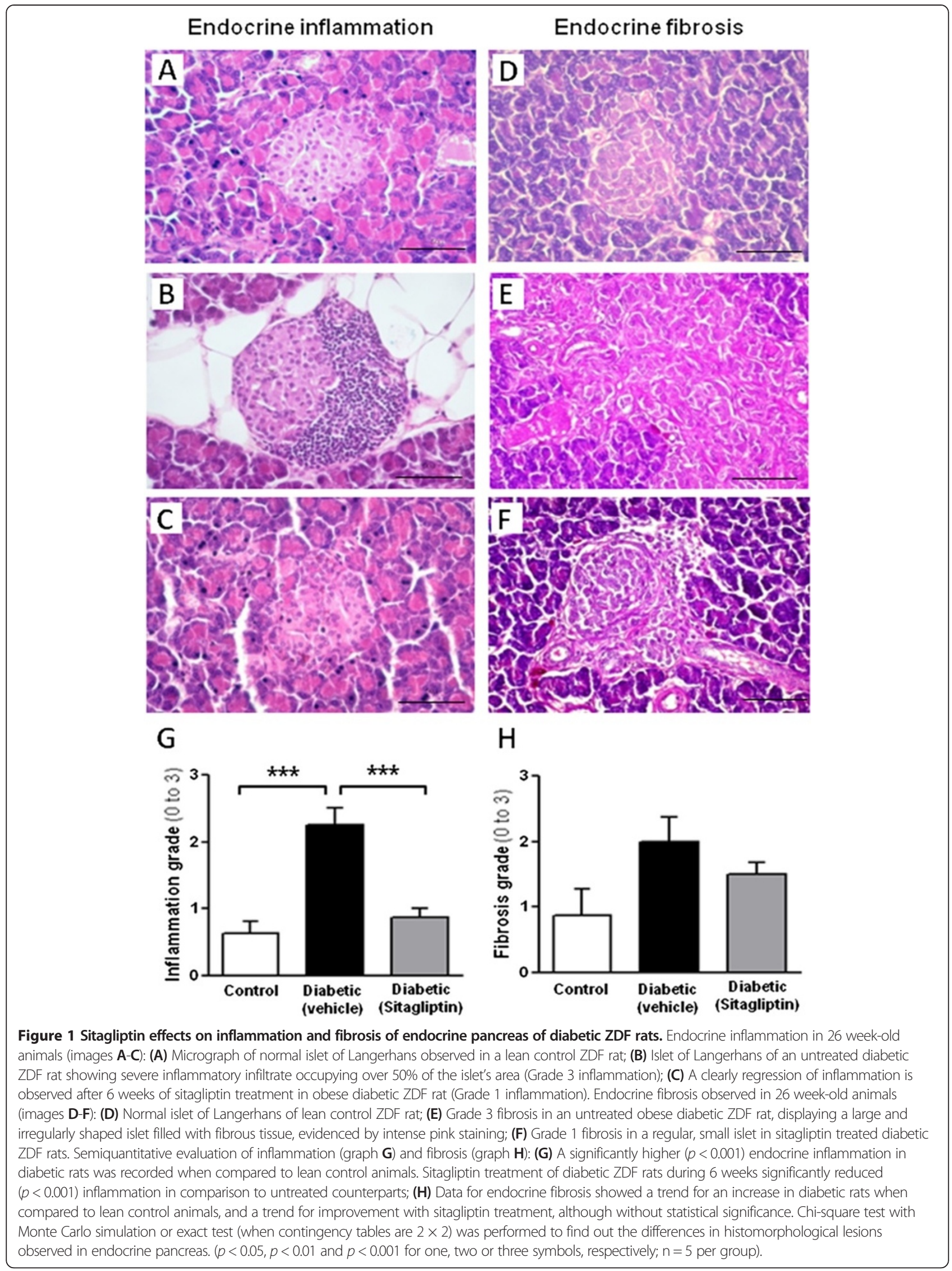




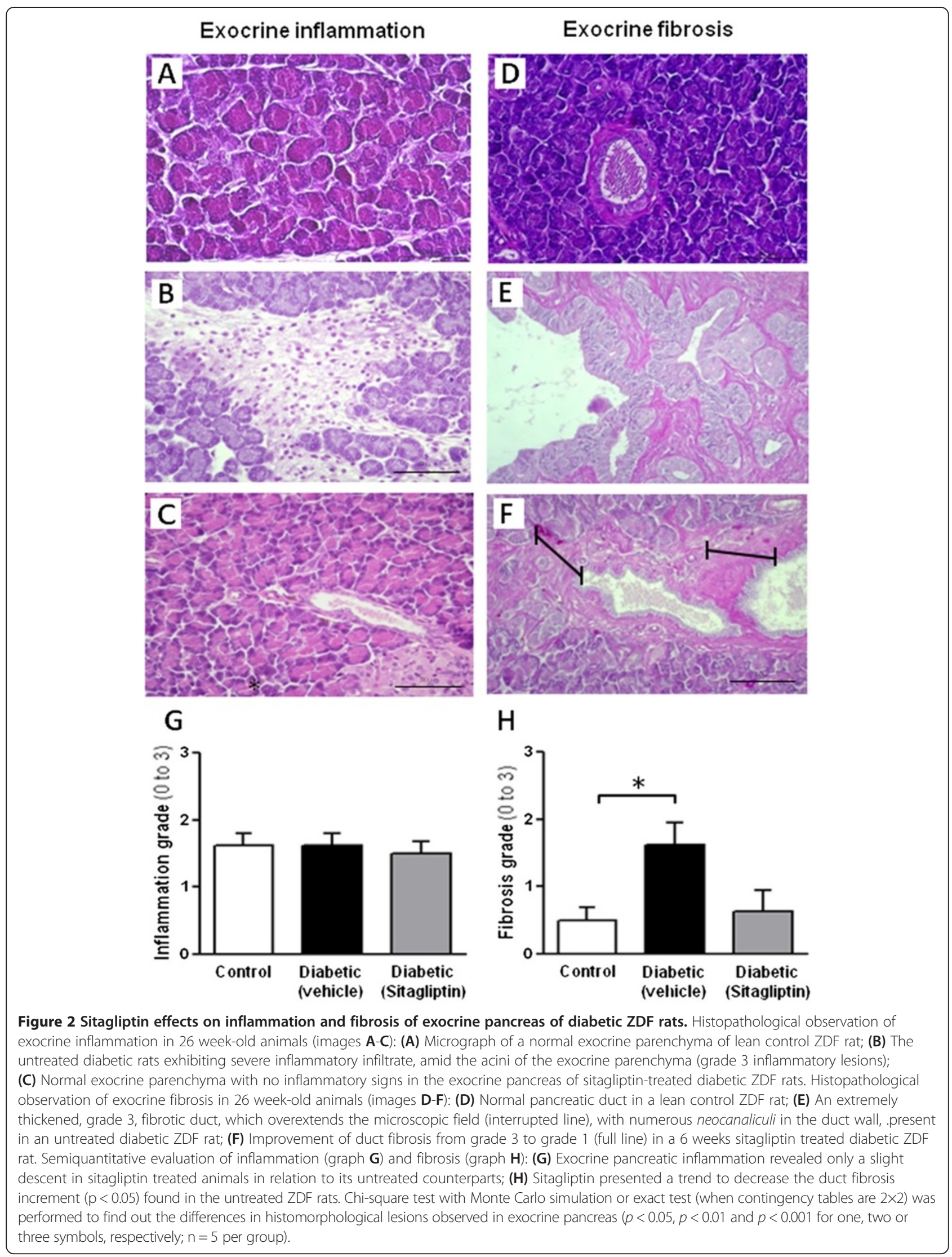




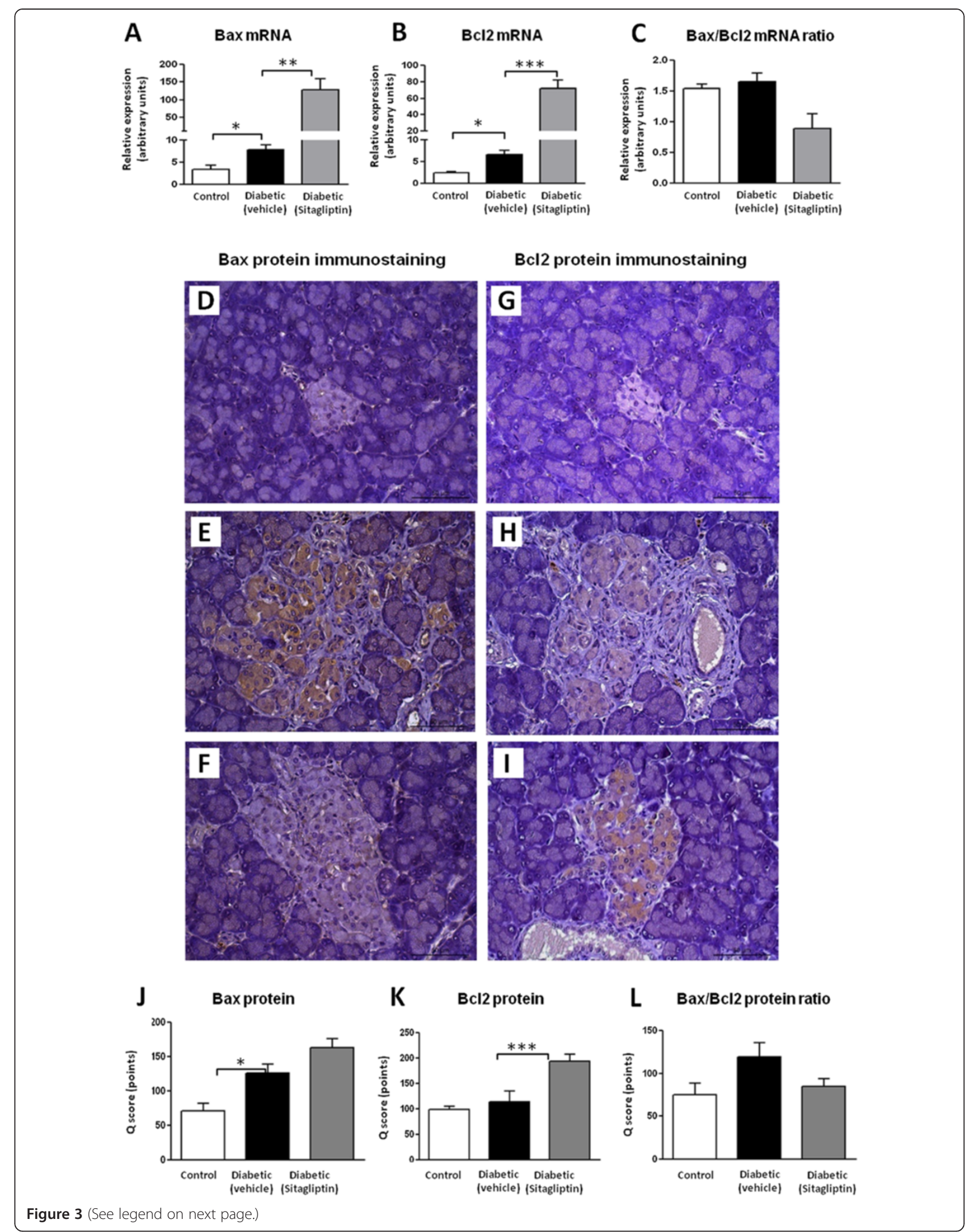


(See figure on previous page.)

Figure 3 Sitagliptin protects the diabetic ZDF rats against endocrine pancreas apoptotic cell death. Upper panel (A-C) - pancreas mRNA expression of Bax and bcl2 in 26 week-old ZDF rats: A significant increase $(p<0.05)$ in apoptotic protein Bax $(\mathbf{A})$, as well as, in antiapoptotic Bcl2 (B) was observed in the untreated diabetic ZDF rats when compared with the lean control ZDF animals, resulting in an unchanged Bax/Bcl2 ratio (C). In the sitagliptin-treated diabetic rats an overexpression of the mRNA was registered for both Bax (not statically significant) and Bcl2 ( $p<0.001$ ) ensuing a reduced $\mathrm{Bax} / \mathrm{BCl} 2$ ratio (C). Middle panel (D-I) - Immunostaining of pancreas Bax and Bcl2 in 26 week-old ZDF rats: (D) The expression of Bax protein is not present in the pancreatic islet (grade 0) of a lean control rat; (E) A deeply stained islet (grade 3) revealing Bax protein expression in untreated diabetic ZDF rat; (F) The diabetic sitagliptin-treated rats displayed a light stained islet (grade 1); (G) Expression of Bcl2 protein not observed in islet (grade 0) of a lean control rat; (H) A moderately stained islet (grade 2) with Bcl2 antibody in an untreated diabetic ZDF rat; (I) An intensely stained islet (grade 3) in a diabetic sitagliptin-treated rat. Lower panel (J-L) - Quantification of protein expression: Bax protein expression in diabetic untreated rats exhibited a significant increase in relation to lean control rats; in sitagliptin-treated diabetic rats, Bax presented a trend for overexpression $(\mathbf{J})$, accompanied by a significantly $(p<0.001)$ increased expression of $\mathrm{BCl} 2(\mathbf{K})$, resulting in a $\mathrm{Bax} / \mathrm{Bcl} 2$ ratio identical to control animals (L). Statistical comparisons between groups were performed using one-way ANOVA and the post-hoc Bonferroni test $(p<0.05, p<0.01$ and $p<0.001$ for one, two or three symbols, respectively; $n=5$ per group).

It is well established that apoptosis is one of the pathways responsible for the progressive deterioration of beta cell and evolution of diabetes. Our study suggests that sitagliptin is able to promote an antiapoptotic effect, which is in agreement with other reports [37-40,44] in the pancreatic tissue. In fact, Matveyenko et al. [36] reported that sitagliptin therapy led to preservation of $\beta$-cell mass in HIP rats as compared with its untreated counterparts, while Maida et al. [38] reported an increment of percentage of $\beta$-cell area in streptozotocin-induced diabetic mice under sitagliptin treatment. The antiapoptotic properties of sitagliptin is also in agreement with the effects reported in extra-pancreatic tissues, such as the kidney, with improvement of renal function and reduction of parenchymal damage, due to a decrease in apoptosis, inflammation and an increase of in antioxidant capacity $[30,40,45,46]$. Apart from the antiapoptotic effect suggested by our results, the protective effects afforded by sitagliptin on the pancreas tissue might be the result of other activities previously described for the incretin peptides, including GLP-1 [15,16,47-51]. Anti-inflammatory, pro-angiogenic and pro-proliferative properties are suggested by the reduced expression of IL-1 $\beta$ and by the increased expression of VEGF and PCNA observed in the pancreas tissue of sitagliptin-treated diabetic rats. Inflammation has been associated with the development of insulin resistance, beta cell apoptosis and evolution of diabetes, and IL- $1 \beta$ is one of the main inflammatory cytokines in the process $[52,53]$. We and other authors have suggested anti-inflammatory properties of gliptins in distinct animal models and tissues, as well as, in type 2 diabetic patients [29,43,45,54-56], in agreement with our hypothesis. VEGF is expressed in the endocrine cells and the increased VEGF expression found in the diabetic rats under sitagliptin treatment might be viewed as an increased capacity for tissue regeneration. The same is true for PCNA, which is an indicator for cell proliferation and has been used in the present work to determine $\beta$-cell mass expansion $[57,58]$. It could be hypothesized that sitagliptin-evoked increased GLP-1 availability, due to inhibition of its degradation by DPP-IV, will favour the development of new cells, via proliferation enhancement of pre-existing cells and induction of islet neogenesis, effects that were previously reported for GLP-1 [27].

The second mechanism involved in the effect of sitagliptin may be related to significant improvement in the metabolic profile, including amelioration of glucose, insulin and TGs levels. We must empathize that the dose
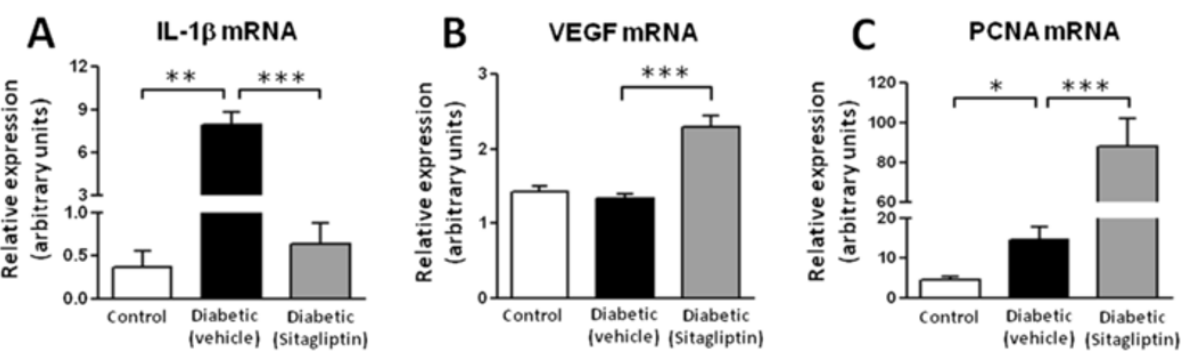

Figure 4 Effects of sitagliptin treatment on pancreatic mRNA expression of mediators of inflammation, angiogenesis and proliferation: IL-1 $\beta$, VEGF and PCNA. (A) mRNA expression of pancreatic IL-1 $\beta$ in untreated diabetic ZDF rats was significantly increased $(p<0.01)$ in contrast to lean control rats; in the sitagliptin-treated diabetic group, overexpression of IL-1 $\beta$ was significantly prevented $(p<0.001)$. Overexpression $(p<0.001)$ of VEGF (B) and PCNA (C) mRNA in ZDF diabetic rats treated with sitagliptin for 6 weeks when compared with untreated diabetic rats. Statistical comparisons between groups were performed using one-way ANOVA and the post-hoc Bonferroni test $(p<0.05, p<0.01$ and $p<0.001$ for one, two or three symbols, respectively; $\mathrm{n}=5$ per group). 
Figure 5 Sitagliptin prevents TRIB3 protein overexpression in pancreas of ZDF diabetic rats. Micrographs of TRIB3 expression by immunostaining in 26 week-old ZDF rats (A-C): (A) Lean ZDF control rat presenting unstained pancreatic islet (grade 0); (B) Untreated diabetic ZDF rat showing an intensely stained pancreatic islet (grade 3); (C) Sitagliptin-treated diabetic rat for 6 weeks displayed light staining of endocrine cells (grade 1). Exocrine pancreatic tissue presents normal constant staining for TRIB3 in all three groups. (D) Quantification of protein expression by score points: expression of TRIB3 is almost undetectable in control rats, rising very significantly $(p<0.001)$ in untreated diabetic ZDF rats; and declining very meaningfully $(p<0.001)$ in 6 weeks sitagliptin-treated diabetic treated rats. Statistical comparisons between groups were performed using one-way ANOVA and the post-hoc Bonferroni test $(p<0.05, p<0.01$ and $p<0.001$ for one, two or three symbols, respectively; $n=5$ per group).

of sitagliptin used in our study (10 mg/ $\mathrm{kg} /$ day $)$ may be considered a low dose as others have used higher doses or a twice a day treatment $[37,38,40]$. Nevertheless, sitagliptin treatment improved hyperglycaemia and hypertriglyceridaemia, thus ameliorating glucolipotoxicity in the diabetic ZDF rats. Several pathophysiological mechanisms have been identified as potential contributors to $\beta$-cell stress and subsequent dysfunction, including glucotoxicity, lipotoxicity, and increased secretory demand resulting from insulin resistance. In addition, disturbances in secretion of various adipose tissue-secreted factors or cytokines derived from the innate immune system might also play a causal role [18]. Furthermore, both hyperglycaemia and hyperlipidaemia are associated with induction of oxidative stress in $\beta$-cells. Previously, we have already demonstrated using this animal model that a low-dose chronic sitagliptin treatment was able to promote a favourable impact on chronic inflammation and oxidative stress [29]. In this context, it should also be noted that the effect of liraglutide upon endoplasmatic reticulum stress, oxidative stress and cell apoptosis in diabetic $d b / d b$ rats, as well as the results of vildagliptin in diabetic $\mathrm{KK}-\mathrm{A}^{y}$ mice, are essentially compatible with those observed in this study $[59,60]$.

Malfunctioning insulin secretion and/or insulin resistance are recognized as key factors for the pathogenesis of T2DM [61,62]; the latter results from anomalies in the insulin signaling cascade, a regulated complex molecular pathway, which may be inhibited and activated by many biochemical mechanisms [62]. One of the genes implicated in coding inhibitors of insulin signaling and action is TRIB3, a mammalian tribbles homolog that binds Akt inhibiting downstream insulin-signalling cascade [62,63]. Our current study revealed that 26 week old ZDF diabetic rats showed pancreas overexpression of TRIB3 which, concurrently, showed insulin resistance and relative insulinopaenia. Sitagliptin treatment was able to completely reduce tissue TRIB3 expression, which might be a key mechanism for the decline of insulin resistance and improvement of insulin secretion observed in the 
diabetic rats under sitagliptin treatment. It has been shown, in cellular and animal models, that changes in TRIB3 expression levels induce systemic insulin resistance [64-66]. Indeed, increased TRIB3 expression was observed in islets from T2DM donors and high fed diet (HFD) mice $[61,63]$. In humans, TRIB3 has also been associated with insulin resistance and T2DM, accompanied by enhanced inhibition of insulin signalling and AKT/PKB activation in different tissues, including the $\beta$ cells $[61,67,68]$. Prior rodent studies [64-66,69], indicate that TRIB3 overexpression plays a major role in modulating whole-body insulin sensitivity and suggest a possible involvement in the pathogenesis of insulin resistance-related metabolic abnormalities. Another pivotal aspect by which TRIB3 seems to be associated with the evolution of insulin resistance and pancreas degradation is its role in inducing apoptosis in pancreatic $\beta$-cells and inhibiting cell proliferation; so, by downregulating the expression of TRIB3, sitagliptin promotes antiapoptotic effects and enhance $\beta$-cell proliferation, thus contributing to the beneficial effects afforded by this DPP-IV inhibitor in this animal model.

\section{Conclusions}

In this animal model of obese type 2 diabetes (the ZDF rat) sitagliptin prevented $\beta$-cell dysfunction and evolution of pancreas damage. The protective effects afforded by this DPP-IV inhibitor may derive from improvement of metabolic profile (related to amelioration of glycaemic and lipidic levels and of insulin resistance) and from cytoprotective properties. In fact, sitagliptin was able to reduce $\mathrm{Bax} / \mathrm{Bcl} 2$ ratio, suggestive of an antiapoptotic effect, and completely prevented the increased pancreas overexpression of IL- $1 \beta$ and TRIB3 found in the untreated diabetic animals, thus demonstrating an anti-inflammatory action; in addition, sitagliptin was able to promote overexpression of VEGF and PCNA, suggesting pro-angiogenic and pro-proliferative properties. From a therapeutic viewpoint, our results reinforce the status of sitagliptin as a promising antidiabetic drug not only by the expected glycaemic control but also, and specially, by the ability to prevent the decline of insulin secreting capacity in pancreatic islets through tissue-cytoprotective properties, thus suggesting a role in the prevention of diabetes evolution.

\footnotetext{
Abbreviations

BW: Body weight; CRP: C-reactive protein; DPP-IV: Dipeptidyl peptidase IV; GIP: Gastric inhibitory polypeptide; GLP-1: Glucagon-like peptide-1; HbA1c: Glycosylated haemoglobin; HE: Haematoxylin and eosin; HFD: High fed diet; HIP: Human IAPP; HOMA: Homeostasis model assessment; IL-1 $\beta$ : Interleukin 1 beta; PAS: Periodic acid of Schiff; PCNA: Proliferating cell nuclear antigen; RT-qPCR: Reverse transcription quantitative polymerase chain reaction; SEM: Standard error of means; T2DM: Type 2 diabetes mellitus; TGs: Triglycerides; TNF-a: tumor necrosis factor alpha; VEGF: Vascular endothelial growth factor; WHO: World Health Organization; ZDF: Zucker Diabetic Fatty.
}

\section{Competing interests}

The authors declare that they have no competing interest.

\section{Authors' contributions}

$C M, F T, R F, F R$ and ETL conceived and designed the study protocol. CM, HV, PR-S, RF, FR and ETL participated in the animal handling and biochemical laboratory assays. HV and PR-S coordinated the histopathological and gene expression studies, respectively. CM, HV, JO, FR and ETL analyzed the data. $\mathrm{CM}, \mathrm{JO}, \mathrm{RF}, \mathrm{FR}$ and ETL prepared the manuscript. FR and ETL equally contributed to the work and are co-last authors and co-responsible for the work and manuscript. All authors read and approved the final manuscript.

\section{Acknowledgements}

The authors gratefully acknowledge The Portuguese Foundation for Science and Technology (FCT) through the projects PEst-C/SAU/UI3282/2013 and PEst-OE/CED/UI4016/2014, and the Center for Studies in Education, Technologies and Health (CI\&DETS) and PROTEC grant by the Polytechnic Institute of Viseu (IPV).

\section{Author details}

${ }^{1}$ Laboratory of Pharmacology \& Experimental Therapeutics, IBILI, Faculty of Medicine, Sub-Unit 1 (Polo III), University of Coimbra, 3000-548 Coimbra, Portugal. ${ }^{2}$ ESAV, Polytechnic Institute of Viseu, Viseu, Portugal. ${ }^{3}$ Center for Studies in Education, Technologies and Health (CI\&DETS), Polytechnic Institute of Viseu, Viseu, Portugal. ${ }^{4}$ Institute of Immunology, Faculty of Medicine, University of Coimbra, Coimbra, Portugal. ${ }^{5}$ Immunology and Oncology Laboratory, Center for Neurosciences and Cell Biology, Coimbra, Portugal.

Received: 30 January 2014 Accepted: 5 March 2014

Published: 20 March 2014

\section{References}

1. World Health Organization: Diabetes Fact sheet $N^{\circ} 312$. In. Updated March 2013; http://www.who.int/mediacentre/factsheets/fs312/en/.

2. Definition, diagnosis and classification of diabetes mellitus and its complications. Part 1: Diagnosis and classification of diabetes mellitus. In. Geneva: World Health Organization; 1999. (WHO/NCD/NCS/99.2). http://www.staff.ncl.ac.uk/philip.home/who_dmg.pdf.

3. Stumvoll M, Goldstein BJ, van Haeften TW: Type 2 diabetes: principles of pathogenesis and therapy. Lancet 2005, 365:1333-1346.

4. Virally M, Blicklé JF, Girard J, Halimi S, Simon D, Guillausseau PJ: Type 2 diabetes mellitus: epidemiology, pathophysiology, unmet needs and therapeutical perspectives. Diabet Med 2007, 33:231-244.

5. Marchetti P, Lupi R, Del Guerra S, Bugliani M, Marselli L, Boggi U: The beta-cell in human type 2 diabetes. Adv Exp Med Biol 2010, 654:501-514.

6. Kahn SE: The Importance of the b-cell in the pathogenesis of type 2 diabetes mellitus. Am J Med 2000, 108:2S-8S.

7. Poitout $V$, Robertson RP, Minireview: Secondary beta-cell failure in type 2 diabetes - a convergence of glucotoxicity and lipotoxicity. Endocrinology 2002, 143(2):339-342.

8. Del Prato S: Role of glucotoxicity and lipotoxicity in the pathophysiology of Type 2 diabetes mellitus and emerging treatment strategies. Diabet Med 2009, 26(12):1185-1192.

9. Creutzfeldt W: The [pre-] history of the incretin concept. Regul Pept 2005, 128(2):87-91.

10. Mclntyre N, Holdsworth CD, Turner DS: New interpretation of oral glucose tolerance. Lancet 1964, 2(7349):20-21.

11. Ranganath LR: The entero-insular axis: implications for human metabolism. Clin Chem Lab Med 2008, 46(1):43-56.

12. Creutzfeldt W: The incretin concept today. Diabetologia 1979, 16(2):75-85.

13. Deacon CF, Nauck MA, Toft-Nielsen M, Pridal L, Willms B, Holst JJ: Both subcutaneously and intravenously administered glucagon-like peptide-1 are rapidly degraded from the $\mathrm{NH}$-terminus in type II diabetic patients and healthy subjects. Diabetes 1995, 44(9):1126-1131.

14. Ranganath LR: Incretins: pathophysiological and therapeutic implications of glucosedependent insulinotropic polypeptide and glucagon-like peptide-1. J Clin Pathol 2008, 61(4):401-409.

15. Gallwitz B: New therapeutic strategies for the treatment of type 2 diabetes mellitus based on incretins. Rev Diabet Stud 2005, 2(2):61-69. 
16. Holst JJ, Gromada J: Role of incretin hormones in the regulation of insulin secretion in diabetic and nondiabetic humans. Am J Physiol Endocrinol Metab 2004, 287(2):E199-E206.

17. Nauck MA, Baller B, Meier JJ: Gastric inhibitory polypeptide and glucagonlike peptide- 1 in the pathogenesis of type 2 diabetes. Diabetes 2004, 53(3):S190-S196.

18. Lin Y, Rajala MW, Berger JP, Moller DE, Barzilai N, Scherer PE: Hyperglycemia-induced production of acute phase reactants in adipose tissue. J Biol Chem 2001, 276:42077-42083.

19. Hotamisligil GS: The role of TNF-and TNF receptors in obesity and insulin resistance. J Intern Med 1999, 245:621-625.

20. Martín-Cordero L, García JJ, Hinchado MD, Ortega E: The interleukin-6 and noradrenaline mediated inflammation-stress feedback mechanism is dysregulated in metabolic syndrome: effect of exercise. Cardiovasc Diabetol 2011, 20:10-42.

21. Huang CJ, Lin CY, Haataja L, Gurlo T, Butler AE, Rizza RA, Butler PC: High expression rates of human islet amyloid polypeptide induce endoplasmic reticulum stress mediated beta-cell apoptosis, a characteristic of humans with type 2 but not type 1 diabetes. Diabetes 2007, 56:2016-2027.

22. Laybutt DR, Preston AM, Akerfeldt MC, Kench JG, Busch AK, Biankin AV, Biden $T$ J: Endoplasmic reticulum stress contributes to beta cell apoptosis in type 2 diabetes. Diabetologia 2007, 50:752-763.

23. Knøp FK, Vilsbø\|l T, Højberg PV, Larsen S, Madsbad S, Vølund A, Holst JJ, Krarup T: Reduced incretin effect in type 2 diabetes: cause or consequence of the diabetic state? Diabetes 2007, 56:1951-1959.

24. Seshadri KG, Kirubha MHB: A new class of oral antidiabetic agents. Indian J Pharm Sci 2009, 71:608-614.

25. Holst JJ, Vilsbø\|l T, Deacon CF: The incretin system and its role in type 2 diabetes mellitus. Mol Cell Endocrinol 2009, 297:127-136.

26. Toft-Nielsen MB, Damholt MB, Madsbad S, Hilsted LM, Hughes TE, Michelsen BK, Holst JJ: Determinants of the impaired secretion of glucagon-like peptide-1 in type 2 diabetic patients. J Clin Endocrinol Metab 2001, 86(8):3717-3723

27. Farilla L, Hui H, Bertolotto C, Kang E, Bulotta A, Di Mario U, Perfetti R: Glucagon-like peptide-1 promotes islet cell growth and inhibits apoptosis in Zucker diabetic rats. Endocrinology 2002, 143:4397-4408.

28. Li Y, Hansotia T, Yusta B, Ris F, Halban PA, Drucker DJ: Glucagon-like peptide- 1 receptor signaling modulates $\beta$ cell apoptosis. J Biol Chem 2003, 278:471-478

29. Ferreira L, Teixeira-de-Lemos E, Pinto F, Parada B, Mega C, Vala H, Pinto R, Garrido P, Sereno J, Fernandes R, Santos P, Velada I, Melo A, Nunes S, Teixeira F, Reis F: Effects of sitagliptin treatment on dysmetabolism, inflammation, and oxidative stress in an animal model of type 2 diabetes (ZDF rat). Mediators Inflamm 2010, 2010:592760.

30. Mega C, de Lemos ET, Vala H, Fernandes R, Oliveira J, Mascarenhas-Melo F, Teixeira F, Reis F: Diabetic nephropathy amelioration by a lowdose sitagliptin in an animal model of type 2 diabetes (Zucker diabetic fatty rat). Exp Diabetes Res 2011, 2011:162092.

31. Teixeira de Lemos E, Reis F, Baptista S, Pinto R, Sepodes B, Vala H, Rocha-Pereira P, Correia da Silva G, Teixeira N, Silva AS, Carvalho L, Teixeira F: Exercise training decreases proinflammatory profile in Zucker diabetic (type 2) fatty rats. Nutrition 2009, 25(3):330-339.

32. Detre S, Saccani Jotti G, Dowsett M: A "quickscore" method for immunohistochemical semiquantitation: validation for oestrogen receptor in breast carcinomas. J Clin Pathol 1995, 48:876-878.

33. Vandesompele J, De Preter K, Pattyn F, Poppe B, Van Roy N, De Paepe A, Speleman F: Accurate normalization of real-time quantitative RT-PCR data by geometric averaging of multiple internal control genes. Genome Biol 2002, 3:RESEARCH0034

34. Livak KJ, Schmittgen TD: Analysis of relative gene expression data using real-time quantitative PCR and the 2- Ä̈̈CT method. Methods 2001, 25:402-408.

35. Brownlee M: A radical explanation for glucose-induced beta cell dysfunction. J Clin Invest 2003, 112:1788-1790.

36. Robertson RP: Chronic oxidative stress as a central mechanism for glucose toxicity in pancreatic islet beta cells in diabetes. $J$ Biol Chem 2004, 279:42351-42354.

37. Aleksey V, Matveyenko AV, Dry S, Cox HI, Moshtaghian A, Gurlo T, Galasso R, Butler AE, Butler PC: Beneficial endocrine but adverse exocrine effects of sitagliptin in the human islet amyloid polypeptide transgenic rat model of type 2 diabetes interactions with metformin. Diabetes 2009, 58(7):1604-1615.
38. Maida A, Hansotia T, Longuet C, Seino T, Drucker DJ: Differential importance of glucose-dependent insulinotropic polypeptide vs glucagon-like peptide 1 receptor signaling for $\beta$ cell survival in mice. Gastroenterology 2009, 137:2146-2157.

39. Yeom JA, Kim ES, Park HS, Ham DS, Sun C, Kim JW, Cho JH, Yoon KH: Both sitagliptin analogue \& pioglitazone preserve the beta-cell proportion in the islets with different mechanism in non-obese and obese diabetic mice. BMB Rep 2011, 44(11):713-718.

40. Maiztegui B, Borelli MI, Madrid VG, Del Zotto H, Raschia MA, Francini F, Massa ML, Flores LE, Rebolledo OR, Gagliardino JJ: Sitagliptin prevents the development of metabolic and hormonal disturbances, increased $\beta$-cell apoptosis and liver steatosis induced by a fructose-rich diet in normal rats. Clin Sci 2011, 120:73-80.

41. Nachnani JS, Bulchandani DG, Nookala A, Herndon B, Molteni A, Pandya P, Taylor R, Quinn T, Weide L, Alba LM: Biochemical and histological effects of exendin-4 (exenatide) on the rat pancreas. Diabetologia 2010, 53(1):153-159.

42. Mu J, Woods J, Zhou YP, Roy RS, Li Z, Zycband E, Feng Y, Zhu L, Li C, Howard AD, Moller DE, Thornberry NA, Zhang BB: Chronic inhibition of dipeptidyl peptidase-4 with a sitagliptin analog preserves pancreatic beta-cell mass and function in a rodent model of type 2 diabetes. Diabetes 2006, 55(6):1695-1704.

43. Gonçalves A, Leal E, Paiva A, Teixeira Lemos E, Teixeira F, Ribeiro CF, Reis F, Ambrósio AF, Fernandes R: Protective effects of the dipeptidyl peptidase IV inhibitor sitagliptin in the blood-retinal barrier in a type 2 diabetes animal model. Diabetes Obes Metab 2012, 14(5):454-463.

44. Nauck MA, Vilsbøll T, Gallwitz B, Garber A, Madsbad S: Incretin-Based Therapies: Viewpoints on the way to consensus. Diabetes Care 2009, 32(2):S223-S231.

45. Joo KW, Kim S, Ahn SY, Chin HJ, Chae DW, Lee J, Han JS, Na KY: Dipeptidyl peptidase IV inhibitor attenuates kidney injury in rat remnant kidney. BMC Nephrol 2013, 14:98

46. Hocher B, Reichetzeder C, Alter ML: Renal and cardiac effects of DPP-4 inhibitors - from preclinical development to clinical research. Kidney Blood Press Res 2012, 36:65-84

47. Ahrén B, Gomis R, Standl E, Mills D, Schweizer A: Twelve- and 52-week efficacy of the dipeptidyl peptidase IV inhibitor LAF237 in metformin-treated patients with type 2 diabetes. Diabetes Care 2004, 27(12):2874-2880.

48. Green BD, Flatt PR, Bailey CJ: Dipeptidyl peptidase IV (DPP IV) inhibitors: A newly emerging drug class for the treatment of type 2 diabetes. Diab Vasc Dis Res 2006, 3(3):159-165.

49. Darnell D, Davis T, GilFillan C, Karrasch J, Lowy A, Bantwal G, Basavanagowdappa H, Chandalia H, Kumar H, Modi K, Paturi V, Seshaiah V, Sethi B, Shah S, Yajnik C, De Mattia G, Ghirlanda G, Hussein Z, Natkunam SK, Ramanathan GR, Sarvar MM, Tan HS, Benatar J, Leikis R, Scott R, Arciszewska M, Babol I, Gabryel A, Krzyczkowska-Bokwa E, Kula M, et al: Efficacy and safety of sitagliptin when added to ongoing metformin therapy in patients with type 2 diabetes. Diabetes Obes Metab 2008, 10(10):959-969.

50. Deacon CF, Holst JJ: Dipeptidyl peptidase IV inhibition as an approach to the treatment and prevention of type 2 diabetes: a historical perspective. Biochem Biophys Res Commun 2002, 294:1-4

51. Gallwitz B: Extra-pancreatic effects of incretin-based therapies. 2014 [Epub ahead of print].

52. Dinarello CA, Donath MY, Mandrup-Poulsen T: Role of IL-1beta in type 2 diabetes. Curr Opin Endocrinol Diabetes Obes 2010, 17(4):314-321.

53. Maedler K, Dharmadhikari G, Schumann DM, Størling J: Interleukin-targeted therapy for metabolic syndrome and type 2 diabetes. Handb Exp Pharmacol 2011, 203:257-278.

54. Lee TI, Kao YH, Chen YC, Huang JH, Hsu MI, Chen YJ: The dipeptidyl peptidase-4 inhibitor-sitagliptin modulates calcium dysregulation, inflammation, and PPARs in hypertensive cardiomyocytes. Int J Cardiol 2013, 168(6):5390-5395.

55. Satoh-Asahara N, Sasaki Y, Wada H, Tochiya M, lguchi A, Nakagawachi R, Odori S, Kono S, Hasegawa K, Shimatsu A: A dipeptidyl peptidase-4 inhibitor, sitagliptin, exerts anti-inflammatory effects in type 2 diabetic patients. Metabolism 2013, 62(3):347-351.

56. Derosa G, Carbone A, D'Angelo A, Querci F, Fogari E, Cicero AF, Maffioli P. Variations in inflammatory biomarkers following the addition of sitagliptin in patients with type 2 diabetes not controlled with metformin. Intern Med 2013, 52(19):2179-2187.

57. Duvillié B, Currie C, Chrones T, Bucchini D, Jami J, Joshi RL, Hill DJ: Increased islet cell proliferation, decreased apoptosis, and greate vascularization leading to beta-cell hyperplasia in mutant mice lacking insulin. Endocrinology 2002, 143(4):1530-1537. 
58. Li X, Zhang L, Meshinchi S, Dias-Leme C, Raffin D, Johnson JD, Treutelaar MK, Burant CF: Islet Microvasculature in Islet Hyperplasia and Failure in a Model of Type 2 Diabetes. Diabetes 2006, 55(11):2965-2973.

59. Shimoda M, Kanda Y, Hamamoto S, Tawaramoto K, Hashiramoto M, Matsuki M, Kaku K: The human glucagon-like peptide-1 analogue liraglutide preserves pancreatic beta cells via regulation of cell kinetics and suppression of oxidative and endoplasmic reticulum stress in a mouse model of diabetes. Diabetologia 2011, 54(5):1098-1108

60. Hamamoto S, Kanda Y, Shimoda M, Tatsumi F, Kohara K, Tawaramoto K, Hashiramoto M, Kaku K: Vildagliptin preserves the mass and function of pancreatic $\beta$ cells via the developmental regulation and suppression of oxidative and endoplasmic reticulum stress in a mouse model of diabetes. Diabetes Obes Metab 2013, 15(2):153-163.

61. Prudente S, Scarpelli D, Chandalia M, Zhang YY, Morini E, Del Guerra S, Perticone F, Li R, Powers C, Andreozzi F, Marchetti P, Dallapiccola B, Abate N, Doria A, Sesti G, Trischitta V: The TRIB3 Q84R Polymorphism and Risk of Early-Onset Type 2 Diabetes. J Clin Endocrinol Metab 2009, 94(1):190-196.

62. Beguinot F: Tribbles homologue 3 (TRIB3) and the insulin-resistance genes in type 2 diabetes. Diabetologia 2010, 53:1831-1834.

63. Prudente S, Sesti G, Pandolfi A, Andreozzi F, Consoli A, Trischitta V: The mammalian tribbles homolog TRIB3, glucose homeostasis, and cardiovascular diseases. Endocr Rev 2012, 33(4):526-546.

64. Liu J, Wu X, Franklin JL, Messina JL, Hill HS, Moellering DR, Walton RG, Martin M, Garvey WT: Mammalian Tribbles homolog 3 impairs insulin action in skeletal muscle: role in glucose-induced insulin resistance. Am J Physiol Endocrinol Metab 2010, 298:E565-E576.

65. Bi XP, Tan HW, Xing SS, Wang ZH, Tang MX, Zhang Y, Zhang W: Overexpression of TRB3 gene in adipose tissue of rats with high fructose-induced metabolic syndrome. Endocr J 2008, 55:747-752.

66. Wang YG, Shi M, Wang T, Shi T, Wei J, Wang N, Chen XM: Signal transduction mechanism of TRB3 in rats with non-alcoholic fatty liver disease. World I Gastroenterol 2009, 15(19):2329-2335.

67. Prudente S, Hribal ML, Flex E, Turchi F, Morini E, De Cosmo S, Bacci S, Tassi V, Cardellini M, Lauro R, Sesti G, Dallapiccola B, Trischitta V: The functional Q84R polymorphism of mammalian Tribbles homolog TRB3 is associated with insulin resistance and related cardiovascular risk in Caucasians from Italy. Diabetes 2005, 54:2807-2811.

68. Gong HP, Wang ZH, Jiang H, Fang NN, Li JS, Shang YY, Zhang Y, Zhong M, Zhang W: TRIB3 functional Q84R polymorphism is a risk factor for metabolic syndrome and carotid atherosclerosis. Diabetes Care 2009 32:1311-1313.

69. Ostertag A, Jones A, Rose AJ, Liebert M, Kleinsorg S, Reimann A, Vegiopoulos A, Berriel Diaz M, Strzoda D, Yamamoto M, Satoh T, Akira S, Herzig S: Control of adipose tissue inflammation through TRB. Diabetes 2010, 59:1991-2000.

doi:10.1186/1758-5996-6-42

Cite this article as: Mega et al: Sitagliptin prevents aggravation of endocrine and exocrine pancreatic damage in the Zucker Diabetic Fatty rat - focus on amelioration of metabolic profile and tissue cytoprotective properties. Diabetology \& Metabolic Syndrome 2014 6:42.

\section{Submit your next manuscript to BioMed Central and take full advantage of:}

- Convenient online submission

- Thorough peer review

- No space constraints or color figure charges

- Immediate publication on acceptance

- Inclusion in PubMed, CAS, Scopus and Google Scholar

- Research which is freely available for redistribution 